\title{
Electronic memory effects in diodes of zinc oxide nanoparticles in a matrix of polystyrene or poly(3- hexylthiophene)
}

\section{Citation for published version (APA):}

Verbakel, F., Meskers, S. C. J., \& Janssen, R. A. J. (2007). Electronic memory effects in diodes of zinc oxide nanoparticles in a matrix of polystyrene or poly(3-hexylthiophene). Journal of Applied Physics, 102(8), 0837011/9. [083701]. https://doi.org/10.1063/1.2794475

DOI:

$10.1063 / 1.2794475$

Document status and date:

Published: 01/01/2007

\section{Document Version:}

Publisher's PDF, also known as Version of Record (includes final page, issue and volume numbers)

\section{Please check the document version of this publication:}

- A submitted manuscript is the version of the article upon submission and before peer-review. There can be important differences between the submitted version and the official published version of record. People interested in the research are advised to contact the author for the final version of the publication, or visit the DOI to the publisher's website.

- The final author version and the galley proof are versions of the publication after peer review.

- The final published version features the final layout of the paper including the volume, issue and page numbers.

Link to publication

\footnotetext{
General rights

- You may freely distribute the URL identifying the publication in the public portal. follow below link for the End User Agreement:

www.tue.nl/taverne

\section{Take down policy}

If you believe that this document breaches copyright please contact us at:

openaccess@tue.nl

providing details and we will investigate your claim.
}

Copyright and moral rights for the publications made accessible in the public portal are retained by the authors and/or other copyright owners and it is a condition of accessing publications that users recognise and abide by the legal requirements associated with these rights.

- Users may download and print one copy of any publication from the public portal for the purpose of private study or research.

- You may not further distribute the material or use it for any profit-making activity or commercial gain

If the publication is distributed under the terms of Article $25 \mathrm{fa}$ of the Dutch Copyright Act, indicated by the "Taverne" license above, please 


\title{
Electronic memory effects in diodes of zinc oxide nanoparticles in a matrix of polystyrene or poly(3-hexylthiophene)
}

\author{
Frank Verbakel, Stefan C. J. Meskers, ${ }^{\text {a) }}$ and René A. J. Janssen \\ Molecular Materials and Nanosystems, Eindhoven University of Technology, P.O. Box 513, 5600 MB \\ Eindhoven, The Netherlands \\ and Dutch Polymer Institute (DPI), P.O. Box 902, 5600 AX Eindhoven, The Netherlands
}

(Received 17 April 2007; accepted 17 August 2007; published online 16 October 2007)

\begin{abstract}
Electronic memory effects in metal-insulator-metal devices with aluminum and poly(3,4-ethylenedioxythiophene):polystyrenesulfonate (PEDOT:PSS) as electrodes and a solution processed active layer consisting of zinc oxide $(\mathrm{ZnO})$ nanoparticles embedded in a matrix of poly(3-hexylthiophene) or polystyrene are investigated. After an initial forming process, the devices show a reversible change in conductivity. The forming process itself is interpreted in terms of desorption of molecular oxygen from the $\mathrm{ZnO}$ nanoparticle surface, induced by injection of holes via the PEDOT:PSS contact, leading to a higher $n$-type conductivity via interparticle $\mathrm{ZnO}$ contacts. The forming can also be induced with ultraviolet light and the process is studied with electron paramagnetic resonance, photoinduced absorption spectroscopy, and field effect measurements. Also, the composition of the active layer is varied and the memory effects can by influenced by changing the $\mathrm{ZnO}$ content and the polymer, allowing for data storage with lifetime $>14$ h. (C) 2007 American Institute of Physics. [DOI: 10.1063/1.2794475]
\end{abstract}

\section{INTRODUCTION}

Resistive switching in metal-insulator-metal (MIM) structures is an intriguing phenomenon in which the electrical resistance can be altered reversibly by the application of a voltage. ${ }^{1-3}$ It is being investigated intensely, partly because of its potential application in data storage. ${ }^{4-8}$ Switching in MIMs has been observed for a very wide variety of insulator materials. Well known are binary oxides (e.g., $\mathrm{Nb}_{2} \mathrm{O}_{5}{ }^{9}$, $\mathrm{Al}_{2} \mathrm{O}_{3},{ }^{10} \mathrm{Ta}_{2} \mathrm{O}_{5},{ }^{11} \mathrm{TiO}_{2},{ }^{12-14} \mathrm{NiO},{ }^{15} \mathrm{Cu}_{2} \mathrm{O},{ }^{16}$ and $\mathrm{ZnO}^{17}$ ), perovskites, $^{18,19}$ polymers (e.g., polystyrene ${ }^{20}$ and melanin ${ }^{21}$, and, more recently, complex molecular materials $^{22-24}$ and mixtures containing inorganic nanoparticles ${ }^{25-30}$ and organic-inorganic interfaces. ${ }^{31}$ Different mechanisms have been proposed to explain resistive switching phenomena, ${ }^{32-37}$ but a large number of reports describe electronic transport via filaments that arise during a so-called forming step of the MIM. ${ }^{1,38-40}$ This forming step occurs under application of a bias voltage and marks the transition from the pristine state of the MIM, which shows no resistive switching effect, to a state in which the resistance can be altered reversibly by application of a voltage.

Recently, we have reported on memory effects in MIM diodes with a mixed insulating layer consisting of $\mathrm{ZnO}$ nanoparticles and polystyrene (PS) polymer. ${ }^{41}$ After a forming step, the resistance of these diodes can be switched by applying voltage pulses of different polarity, and this switching effect resembles that reported for bulk $\mathrm{ZnO} .^{17,42}$ The forming reaction in this material occurs upon illumination with ultraviolet (UV) light or upon application of a high forward bias voltage. We have ascribed the forming process to release of oxygen molecules from the surface of the nanoparticles induced by positive charge carriers in the particle. In this view,

${ }^{a)}$ Electronic mail: s.c.j.meskers@tue.nl the surface bound oxygen acts as an electron trap, depleting the $n$-type $\mathrm{ZnO}$ particles of their mobile charge carriers. Introduction of holes, either via photogeneration ${ }^{43}$ or injection through a contact, results in desorption of molecular oxygen $\left(\mathrm{O}_{2}\right)$ from the surface of the nanoparticle, and the disappearance of the trap site associated with the oxygen allows for a higher concentration of mobile, negatively charged carriers ${ }^{44}$ (Fig. 1). Electrical conductivity through the material was postulated to occur via interparticle contacts and a percolating network. Consistent with this view, the forming process can be reversed by exposure to oxygen and inhibited by surface modification of the $\mathrm{ZnO}$ particles with insulating, aliphatic molecules that form a soft shell around the particles. ${ }^{45}$ At present, the origin of the reversible change in resistance that can be observed after the forming step is not known. It seems plausible that an electrochemical process at the inter-

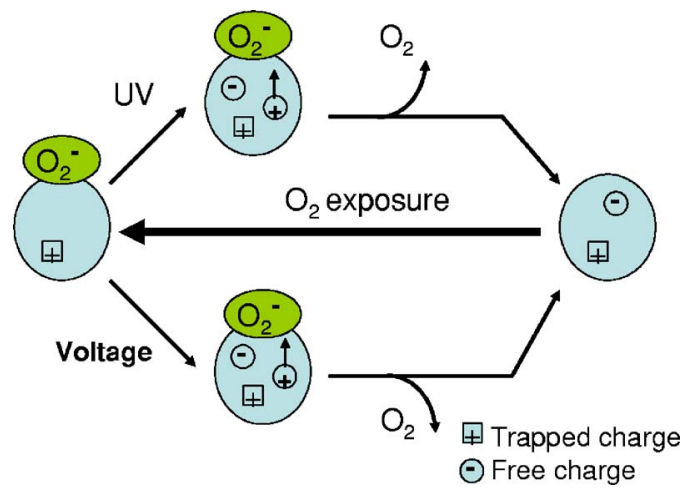

FIG. 1. (Color online) Schematic representation of the UV light and bias voltage induced changes in the $\mathrm{ZnO}$ particles. An injected or photogenerated hole induces desorption of oxygen by recombining with the electron trapped at the $\mathrm{O}_{2}$. After elimination of the $e^{-}$trap site formed by surface bound $\mathrm{O}_{2}$, mobile photogenerated or injected electrons can contribute to a higher conductivity of the material comprising the $\mathrm{ZnO}$ particles. 
face of the $\mathrm{ZnO}$ :PS layer and one of the contacts is involved.

In this paper, we investigate the forming process in the $\mathrm{ZnO}$ :PS diodes in more detail by probing the mobile charge carriers after UV illumination directly, using magnetic resonance and photoinduced absorption spectroscopy. The action of electrically injected holes will be investigated using three electrodes in a field effect transistor geometry. We then investigate MIM devices containing $\mathrm{ZnO}$ blended with polymer, varying the loading of the $\mathrm{ZnO}$ particles in order to investigate the percolation behavior. In addition, we also study a hybrid material consisting of $\mathrm{ZnO}$ nanoparticles blended with a polymer with semiconducting properties: poly(3-hexylthiophene) (P3HT). The results are consistent with electrical transport via the nanoparticles. The fact that the active layer is built up from nanoparticles and polymer allows one to influence the memory effects by changing the $\mathrm{ZnO}$ loading and the nature of the polymer. The minimum write time, on/off ratio, and retention time for rewritable data storage are evaluated for the $\mathrm{ZnO}$ :polymer MIM structures.

\section{EXPERIMENT}

The devices studied consist of a spin coated active layer between two electrodes. The bottom electrode is tin-doped indium oxide (ITO) with a spin coated film of poly $(3,4-$ ethylenedioxythiophene):polystyrenesulfonate (PEDOT:PSS, H.C. Starck, Baytron P VP Al 4083) of $0.7 \times 10^{2} \mathrm{~nm}$ thickness. The active layer is spin coated at $1500 \mathrm{rpm}$ from a solution containing $\mathrm{ZnO}$ particles and $20 \mathrm{mg}$ PS $\left(M_{w}\right.$ $=250 \mathrm{~kg} / \mathrm{mol}$, polydispersity index of 2.2 ) or $10 \mathrm{mg}$ regioregular P3HT (product code 4002, 98.5\% regioregularity, Rieke Metals, Inc.) per milliliter chloroform. ZnO nanoparticles (NPS) were synthesized by reacting zinc acetate with potassium hydroxide in methanol. ${ }^{46}$ The ZnO NPS (average diameter of $5 \mathrm{~nm}$ ) are precipitated, washed, centrifuged, and finally dissolved in chloroform. The nanoparticle suspensions are used within a week after preparation to avoid clustering of the particles. Volume fractions of $\mathrm{ZnO}$ were calculated using a density of $5.6 \mathrm{~g} / \mathrm{cm}^{3}$. The top electrode is made by evaporation of aluminum $(100 \mathrm{~nm})$. The active device area is $9.5 \mathrm{~mm}^{2}$. After deposition of $\mathrm{Al}$, the devices are stored and characterized in an inert atmosphere $\left(\mathrm{O}_{2}, \mathrm{H}_{2} \mathrm{O}\right.$ $\leqslant 1 \mathrm{ppm}$ ). A Keithley 2400 source-measure unit is used for electrical characterization, where positive (forward) bias voltage is defined by the PEDOT electrode being charged positive. In order to determine the forming voltage, the bias voltage applied is increased in steps of $1 \mathrm{~V}$ until the current through the diode reaches a compliance level (100 mA). The effect of irradiation was studied with light from a tungstenhalogen source (total $80 \mathrm{~mW} / \mathrm{cm}^{2}$ ). A cutoff filter, blocking light with wavelength $<400 \mathrm{~nm}$, was used to distinguish effects of UV and visible illumination. Electron paramagnetic resonance (EPR) at $9.43 \mathrm{GHz}(X$-band) was measured with a Bruker ESP 300E spectrometer using a cavity with a $50 \%$ transmission grid. In this setup, the sample can be illuminated with light from a $500 \mathrm{~W}$ Xe light source. The field effect transistor measurements are performed with a HP4155c semiconductor analyzer. A ring transistor with a channel length of $10 \mu \mathrm{m}$ and a channel width of $1000 \mu \mathrm{m}$ is used. Near steady-state photoinduced absorption (PIA) spectra for spin coated films of $\mathrm{ZnO} \mathrm{NP}$ deposited on quartz were recorded between 0.30 and $2.5 \mathrm{eV}$, exciting the film with $3.5 \mathrm{eV}$ photons from mechanically modulated $(73 \mathrm{~Hz}) \mathrm{cw}$ argon ion laser beam. The sample was kept in a chamber, which could be evacuated or filled with air to test the influence of oxygen. During the spectroscopic experiment, the sample was then either continuously in air or in vacuum. The periodic change in the transmission of a tungsten-halogen probe beam through the sample $(\Delta T)$ is measured with a phase-sensitive lock-in amplifier after dispersion through a monochromator and detection using $\mathrm{Si}$, InGaAs, and cooled InSb detectors. The pump power was typically $50 \mathrm{~mW}$ with a beam diameter of $2 \mathrm{~mm}$. The PIA signal $(\Delta T / T)$ was corrected for the photoluminescence, which was recorded in a separate experiment.

\section{RESULTS}

\section{Introduction of mobile charge carriers in ZnO by UV illumination or injected holes}

In Fig. 2(a), we show EPR spectra of the $\mathrm{ZnO}$ nanoparticles in vacuum. Initially, no EPR signal is observed, but after illumination with UV light, an intense EPR signal appears at $g=1.964$ which has been assigned to conduction electrons or weakly bound electrons originating from a shallow donor. ${ }^{47-49}$ Upon exposure to air, this signal is reduced approximately 50 times and shifts to slightly higher field $(g=1.962)$. This demonstrates that the concentration of mobile electrons can be raised with UV illumination and lowered by exposure to oxygen.

Mobile electrons in $\mathrm{ZnO}$ also give rise to absorption of infrared light. ${ }^{46,50}$ This allows probing the charge carriers induced by UV illumination using photoinduced absorption (PIA) spectroscopy. In Fig. 2(b), we show the results of a PIA experiment in which the intensity of the UV excitation beam ( $3.5 \mathrm{eV}$ photon energy) is modulated and the amplitude of the periodic oscillation of the transmission of (white) light resulting from the induced absorption is recoded using phase-sensitive detection. As can be seen, UV illumination gives rise to a PIA signal in the infrared region of the spectrum $(0.3 \mathrm{eV})$ which we ascribe to electrons in the conduction band. In oxygen atmosphere, the signal is much more intense, which can be explained by the fact that mobile electrons generated during the half-period in which the $\mathrm{ZnO}$ is illuminated with UV light can be trapped again by $\mathrm{O}_{2}$ during the dark half-period of the modulation cycle. In the absence of $\mathrm{O}_{2}$, the mobile electrons generated cannot be scavenged and this results in a much smaller modulation of the number of mobile electrons in the absence of $\mathrm{O}_{2}$ and a reduced differential absorption signal in the modulation experiment. In addition, the mobile electrons may quench newly generated excitons by a fast Auger recombination, limiting the photogeneration of additional carriers and suppressing the PIA response. The dependence of the PIA signal on the modulation frequency [Fig. 2(c)] gives information on the lifetime of the charge carriers. In vacuum, the induced differential transmission $(\Delta T)$ decreases with increasing frequency approximately as $|\Delta T(\omega)| \propto \omega^{-1 / 3}$. Fourier transformation of the fre- 

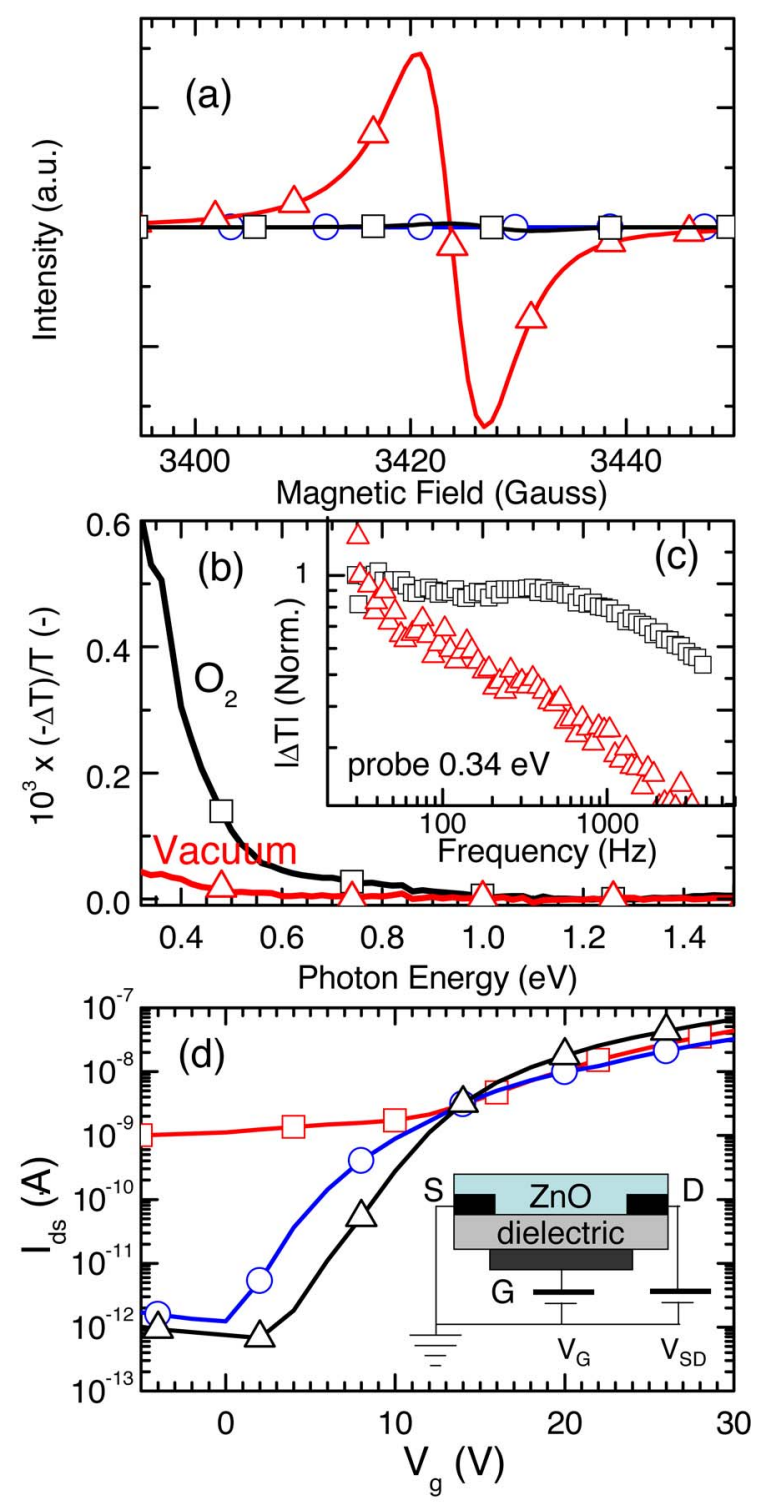

FIG. 2. (Color online) Electron paramagnetic resonance (EPR) of pristine $\mathrm{ZnO}$ NPs in vacuum $(\bigcirc)$, after UV illumination and in vacuum $(\triangle)$, and after subsequent exposed to air $(\square)$. (b) Near steady-state, photoinduced absorption (PIA) of $\mathrm{ZnO}$ NPs on quartz in air $(\square)$ and in vacuum $(\triangle)$. (c) Frequency dependence of the PIA signal at $0.34 \mathrm{eV}$ in air $(\square)$ and in vacuum $(\triangle)$. (d) Transfer characteristics of a field effect transitor $\left(V_{\mathrm{SD}}\right.$ $=+40 \mathrm{~V})$ with channel length $10 \mu \mathrm{m}$ and width $1000 \mu \mathrm{m}$ in vacuum $(\triangle)$, after $V_{G}=-40 \mathrm{~V}$ during $5 \mathrm{~s}(\square)$, and exposed to air ( $\left.\bigcirc\right)$.

quency dependent response gives an indication of the corresponding time dependence of the signal, ${ }^{51}|\Delta T(t)|$ $\propto t^{-2 / 3}$. In air, the differential transmission shows a much flatter frequency dependence, implying a faster decay process. In particular, the flat response up to $1000 \mathrm{~Hz}$, implies the presence of charge carriers with a lifetime shorter than $1 \mathrm{~ms}$. This short lifetime is consistent with the proposed scavenging of mobile electrons by $\mathrm{O}_{2}$. This also gives some indication on how quickly the transition from the high to the low conductivity state through binding of oxygen may occur in the case where $\mathrm{O}_{2}$ is present in close proximity to the $\mathrm{ZnO}$ particles $(<1 \mathrm{~ms})$.

In order to see which of the two types of photogenerated charge carriers induces the doping process, we have applied the $\mathrm{ZnO}$ particles as active layer in a field effect transistor (FET) ${ }^{52,53}$ In Fig. 2(d), we illustrate the transfer characteristics of the device. In vacuum, in the pristine state, the source drain current increases sharply for positive gate voltages, showing that the $\mathrm{ZnO}$ particles behave as an $n$-type semiconductor with an electron mobility on the order of $10^{-4} \mathrm{~cm}^{2} / \mathrm{V} \mathrm{s}$ in the saturation regime. The device characteristics remain unaltered after application of positive gate voltages $(+40 \mathrm{~V})$ for short times, but upon application of negative gate voltages $(-40 \mathrm{~V}, 5 \mathrm{~s})$, the transfer characteristic change drastically, showing a much higher conductivity at zero gate voltage. This shows that the introduction of positive charge carriers by application of the negative gate voltage induces a transition in the material to a state with a much higher conductivity. After exposure to $\mathrm{O}_{2}$, the transfer characteristics of the $\mathrm{ZnO}$ transistor resemble again those for the pristine device.

In summary, the experiments illustrated in Fig. 2 demonstrate that positive charge carriers in the $\mathrm{ZnO}$, either photogenerated or injected via a contact, induce a change in the particles leading to a state with a higher concentration of mobile charge carriers (electrons) in the particles. In an interpretation that also takes into account the persistent photoconductivity and the release of $\mathrm{O}_{2}$, the holes recombine with the electron trapped at the surface of the $\mathrm{ZnO}$ by an $\mathrm{O}_{2}$ molecule, inducing desorption of neutral $\mathrm{O}_{2}{ }^{54,55}$ After desorption, the $\mathrm{O}_{2}$ can no longer act as an electron trap and this allows for an increase in the number of mobile electrons (see Fig. 1), which themselves can be either photogenerated or supplied via an electrical contact. With this mechanistic information, we can now turn our attention to the forming reaction of the $\mathrm{ZnO}$ particles embedded in the diode structure.

\section{Current-voltage characteristics of diodes with ZnO:PS as active layer}

In this section, we describe the electrical properties of MIM devices with an insulating layer consisting of $\mathrm{ZnO}$ and polystyrene. The layout of the diodes used to study the memory effects is illustrated in Fig. 3. The spin coated active layer is sandwiched between two different electrodes, PEDOT:PSS and aluminum. By changing the weight ratio of $\mathrm{ZnO}$ and $\mathrm{PS}$ in the solution used for spin coating, the composition of the active layer can be varied in a systematic way.

In Fig. 3, we illustrate current-voltage $(J-V)$ characteristics of a device in various states. The pristine device shows rectifying behavior and, considering the $n$-type nature of the $\mathrm{ZnO}$ and the Ohmic contact between $\mathrm{ZnO}$ and $\mathrm{Al},{ }^{56}$ the high current densities under positive bias can be attributed to electrons injected through the $\mathrm{Al}$ electrode. More detailed analysis of the $J-V$ characteristics shows that, under forward bias, the current is dominated by an Ohmic (leakage) contribution for voltages below $+0.5 \mathrm{~V}$. For voltages higher than $+0.5 \mathrm{~V}$, we observed a sharp rise of the current density with increasing voltage, which eventually flattens and approaches a $J$ $\propto V^{2}$ behavior, which may be expected for space charge limited conduction. This shows that, at low voltages $(V \leqslant+0.5 \mathrm{~V})$, the active layer behaves as a semiconductor 


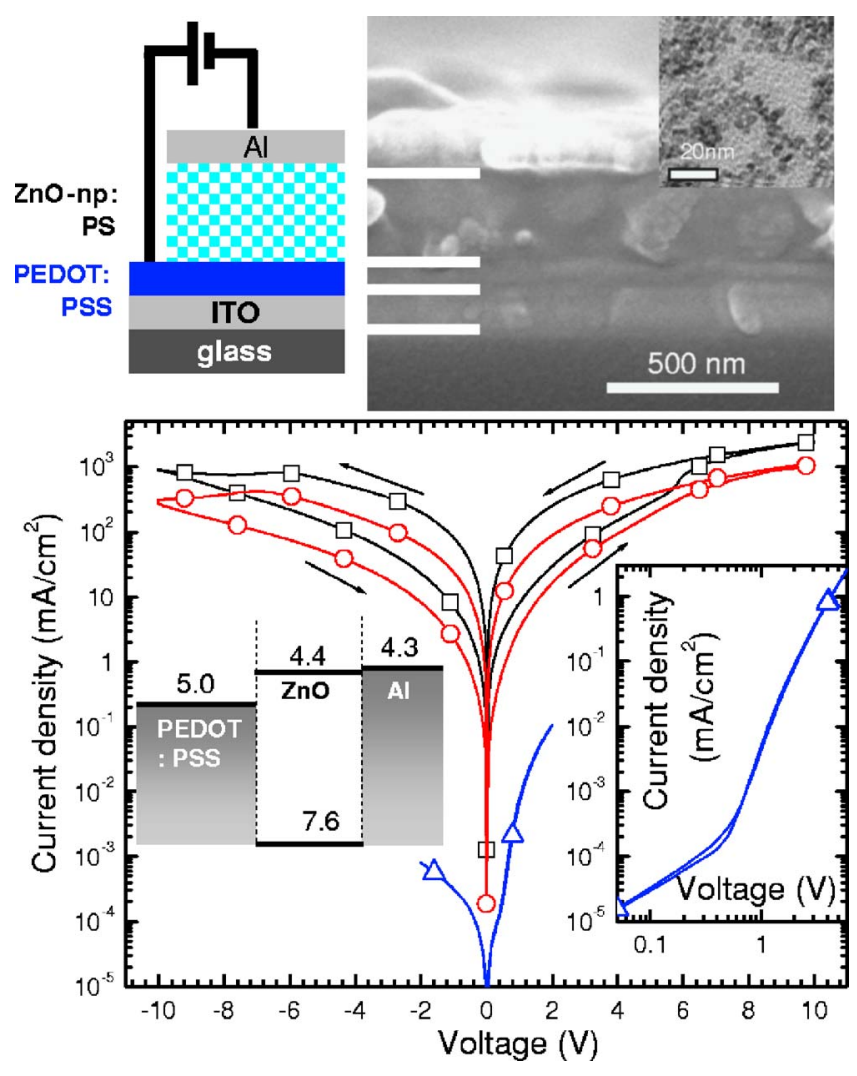

FIG. 3. (Color online) (Top) Cross sectional scanning electron microscopy (SEM) image with a schematic representation of the device structure ( $\mathrm{ZnO}: \mathrm{PS}=1: 2$ by weight) showing the bottom ITO/PEDOT:PSS electrode, the active layer, and the top $\mathrm{Al}$ electrode. (Inset) TEM image of the $\mathrm{ZnO}$ NPs. (Bottom) $J-V$ characteristics of a device with $\mathrm{ZnO}: \mathrm{PS}=1: 2$ unformed $(\triangle)$ and formed in two manners with UV illumination $(10 \mathrm{~s})(\bigcirc)$ or with an applied voltage $(+17 \mathrm{~V})(\square)$. The arrows show the scan direction $(0 \mathrm{~V}$ $\rightarrow+10 \mathrm{~V} \rightarrow-10 \mathrm{~V} \rightarrow 0 \mathrm{~V})$. A diagram, indicating the energetic position in $\mathrm{eV}$ of the conduction and valence bands with respect to the vacuum level, is shown on the left.

with a very low density of mobile carriers. The sharp increase in current density at $+0.5 \mathrm{~V}$ may arise from a built-in voltage resulting from the use of two different electrodes ${ }^{57}$ but may also be influenced by trap filling effects. ${ }^{58}$ Experiments with different metal to electrodes $(\mathrm{Ca}, \mathrm{Pd})$ yielded similar high current densities and also an onset of the current at $+0.5 \mathrm{eV}$, indicating that also with these metals an Ohmic contact is formed. In the case of $\mathrm{Pd}$, formation of an Ohmic contact can only be expected if the $\mathrm{ZnO}$ at the interface with the metal is doped.

After illumination of the diode with UV light through the transparent contact in a short time interval, the $J-V$ characteristics of the diode change drastically (see Fig. 3) The current densities are much higher, the rectifying behavior is strongly suppressed, and a considerable hysteresis appears when performing a cyclic $J-V$ scan. Very similar characteristics can be obtained by applying forward bias stress to the device $(+17 \mathrm{~V},<1 \mathrm{~s})$ instead of illumination with UV light. We ascribe this forming process to the action of holes that are either photogenerated or injected electrically and which raise the density of mobile electrons in the $\mathrm{ZnO}$ particles as explained above. In this interpretation, we assume that electrical conduction in the device occurs via interparticle con-

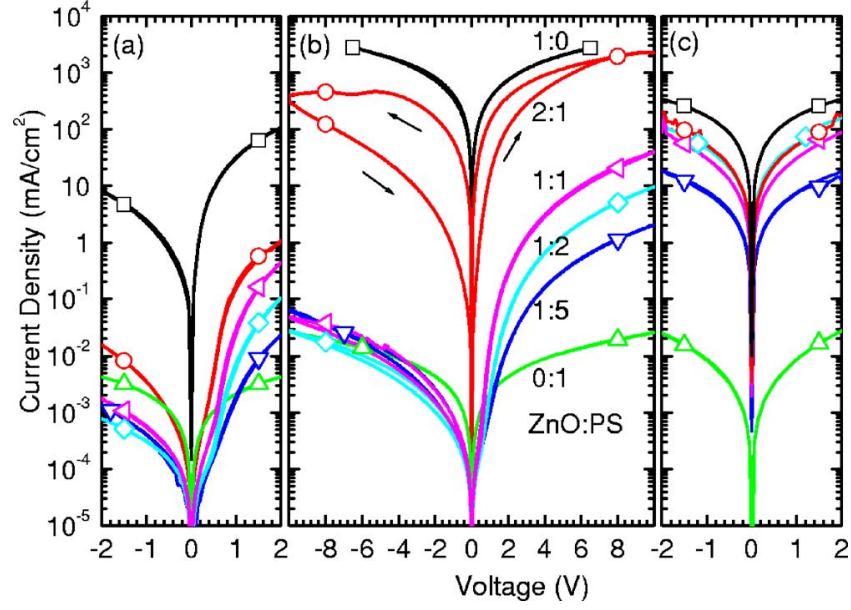

FIG. 4. (Color online) Current density vs voltage of $\mathrm{ZnO}: \mathrm{PS}$ devices with varying weight fractions of $\mathrm{ZnO}$ in the pristine state before forming (a) and after forming by an applied voltage (b) or by UV illumination (10 s) (c). $\mathrm{ZnO}: \mathrm{PS}=1: 0(\square), 2: 1(\bigcirc), 1: 1(\triangleleft), 1: 2(\diamond), 1: 5(\nabla)$, and $0: 1(\triangle)$ (by weight).

tacts. Therefore, one expects a large variation of the electrical properties of the devices with the $\mathrm{ZnO}$ content of the active layer.

To test this idea, we have characterized a series of devices with different $\mathrm{ZnO} \mathrm{NP}$ contents in the active layer. $J-V$ characteristics for this set of devices in their pristine state are shown in Fig. 4(a). Figure 4(b) shows the current densities when performing a cyclic $J-V$ scan from $0,+10,-10$, to $0 \mathrm{~V}$, while Figure 4(c) shows the densities after illumination of pristine devices with UV light for $10 \mathrm{~s}$. As expected, the device with neat polystyrene shows only low current densities. UV illumination and application of bias voltage stress (+20 V for $30 \mathrm{~s})$ have only a negligible effect on the electrical properties of this device.

For the devices containing $\mathrm{ZnO}$ particles, the electrical properties depend on the $\mathrm{ZnO}$ content of the film. The current density through the pristine devices measured at $+2 \mathrm{~V}$ increases with the volume fraction of $\mathrm{ZnO}$ in the active layer (Fig. 5). Scanning the voltage over the $+10 /-10 \mathrm{~V}$ range in the $J-V$ measurement, we notice that the device with a $\mathrm{ZnO}: \mathrm{PS}$ ratio of $2: 1$ undergoes a forming reaction and the current density at $+2 \mathrm{~V}$ is now markedly enhanced in comparison with the pristine devices scanned to bias voltages up to $+2 \mathrm{~V}$. Diodes with a lower $\mathrm{ZnO}$ content also undergo a forming reaction but at a much higher voltage (Fig. 5).

All the diodes in the series containing $\mathrm{ZnO}$ show a significant change in $J-V$ behavior upon illumination with $\mathrm{UV}$ light. The current densities probed at $-2 \mathrm{~V}$ for devices with different $\mathrm{ZnO}$ contents do not differ by more than an order of magnitude, which indicates that the $\mathrm{ZnO}$ volume fraction exceeds the threshold for percolation in all devices. ${ }^{59-62}$ For the unformed diodes, no clear percolation threshold can be observed, which may be related to a large resistance associated with the interparticle contacts that changes gradually with the interparticle separation and contact area. ${ }^{63-65}$

In many metal oxides, hysteresis in the $J-V$ characteristic is associated with sudden jumps in the current density that occur in certain voltage ranges. In contrast, the hysteresis in 


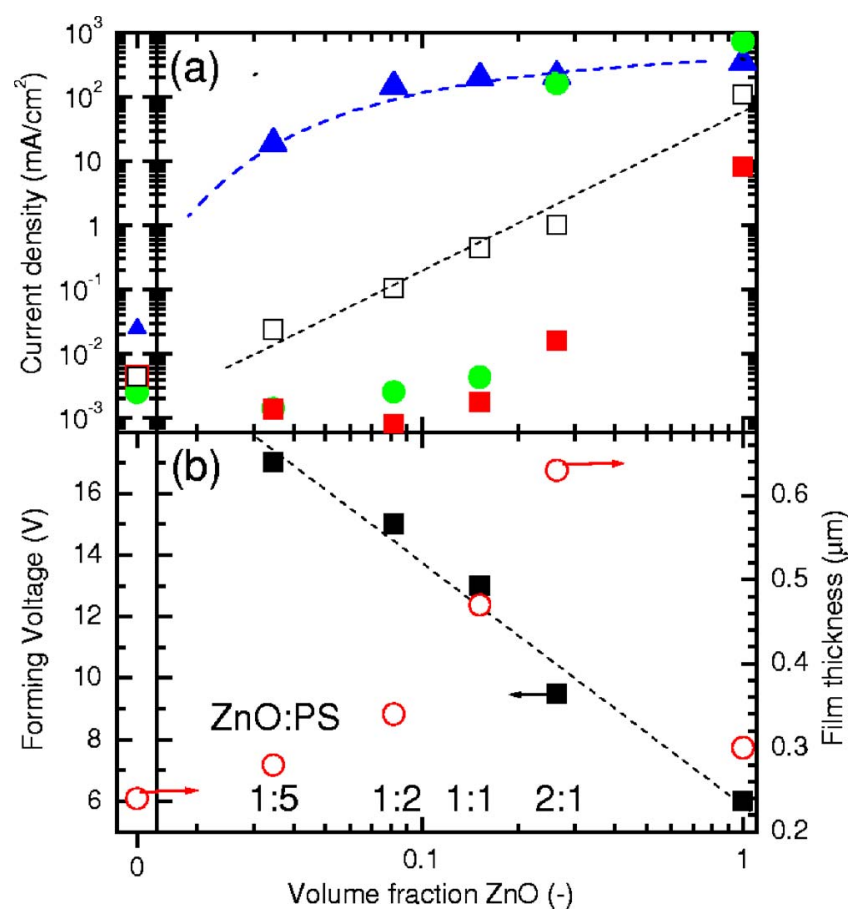

FIG. 5. (Color online) (a) Current density of $\mathrm{ZnO}$ :PS devices vs volume fraction $\mathrm{ZnO}$. Current density $J$ at forward bias, $+2 \mathrm{~V}(\square)$, and at reverse bias, $-2 \mathrm{~V}$, of the pristine device $(\boldsymbol{\square}) . J$ at $-2 \mathrm{~V}$ after voltage forming (O) and after UV illumination ( $\boldsymbol{\Delta})$ forming (15 s). (b) Forming voltage ( $\boldsymbol{\square})$ and film thickness $(\mathrm{O})$ vs volume fraction $\mathrm{ZnO}$. For devices without $\mathrm{ZnO}$, no forming was observed.

the $\mathrm{ZnO}$ :PS diodes studied here is associated with a gradual change in the current density that occurs in the voltage range of +6 to $+9 \mathrm{~V}$. This is illustrated in Fig. 6(a), which shows the $J-V$ traces for a formed device that is subjected to a series of $J-V$ sweeps in which the maximal amplitude of the voltage sweep is increased in steps. As can be seen, cyclic $J-V$ scans with $V$ in the range of -5 to $+5 \mathrm{~V}$ do not show any significant hysteresis, but upon extending the range of voltage sweep, the hysteresis gradually develops.

Application of negative bias voltages results in a decrease of the conductivity of the ZnO:PS devices. Also, this "erase" process is a gradual transition and this is illustrated in Fig. 6(b) where we show a series of cyclic $J-V$ scans in which the voltage is scanned from $0,+8,-X$, to $0 \mathrm{~V}$, with $X$ incremented in steps. As can be seen, the high conduction level, induced by application of $+8 \mathrm{~V}$ bias, can be "erased" in a continuous manner. Models for the memory effect in oxide layers have been proposed in which a single (metallic) filament supports the high current density and where single events such as rupture can switch the conduction "on" and "off." 66,67 Given the gradual change in conduction levels observed for the $\mathrm{ZnO}: \mathrm{PS}$, these models do not apply to the memory effects reported here.

We have also investigated whether reversible changes in the conductivity can be brought about by application of bias voltage pulses of one polarity, or whether application of voltage pulses of both polarities is needed to induce the switching effects. Switching of the resistance using voltage pulses of only one polarity but different voltages is well known for metal oxide MIMs (Ref. 1) and is associated with the occur-

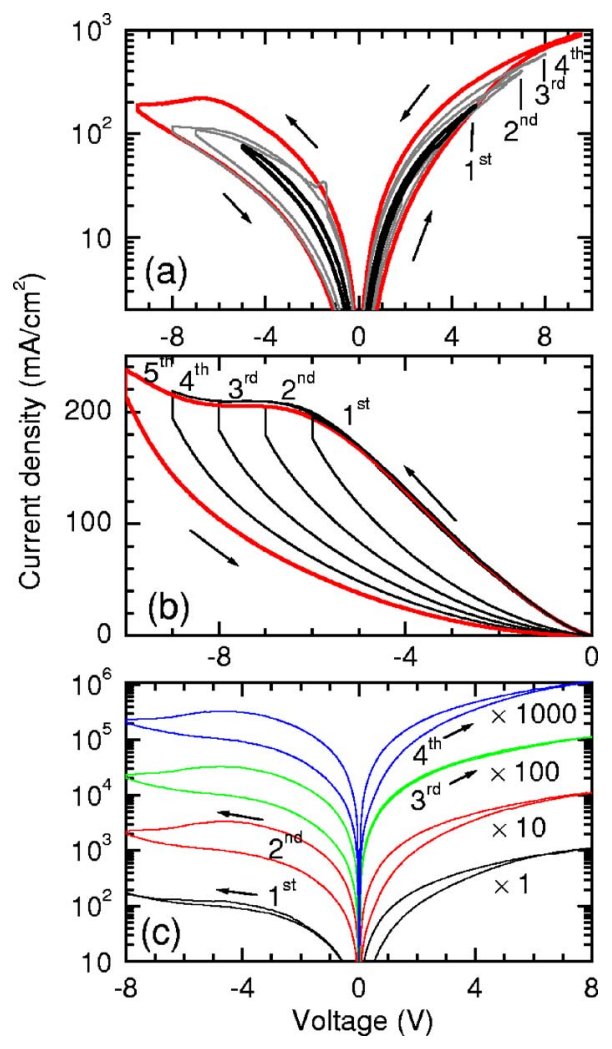

FIG. 6. (Color online) $J-V$ characteristics of a formed $\mathrm{ZnO}$ :PS diode (1:2 by weight). Sequential, cyclic $J-V$ scans with (a), incrementing the maximum amplitude $X$ of the sweep in steps $(0 \rightarrow+X \rightarrow-X \rightarrow 0 \mathrm{~V}$, with $X=5,7,8$, and $9 \mathrm{~V}$ ), (b) incrementing the maximum negative amplitude of the sweep (from $0,+8,-X$, to $0 \mathrm{~V}$, with $X=5,6,7,8$, and $9 \mathrm{~V}$ ), and (c) changing scan direction: preparation scan (from $0,+8,-8$, to $0 \mathrm{~V}$; not shown), first $(0,-8$, $+8,0 \mathrm{~V}$ ), second (from $0,-8,+8$, to $0 \mathrm{~V}$ ), third (from $0,+8,-8$, to $0 \mathrm{~V}$ ), and fourth $(0,+8,-8,0 \mathrm{~V})$. The arrow indicates the initial direction of the bias voltages sweep.

rence of voltage controlled negative differential resistance (VCNR) as explained by, e.g., Simmons and Verderber. ${ }^{34}$ To test for unipolar switching, we have taken a formed $\mathrm{ZnO}$ :PS diode and prepared it by sweeping the voltage in the direction from $0,+8,-8$, to $0 \mathrm{~V}$. After this preparation, the voltage was swept over from $0,-8,+8$, to $0 \mathrm{~V}$ [Fig. 6(c), first $J-V$ trace] and, as can be seen, no hysteresis occurs in the negative leg of the $J-V$ trace and the device is in its low conductivity state. This shows that the conductivity cannot be raised by application of negative bias voltage but is raised only by application of positive bias voltages; see the positive limb of the first trace. From the second scan (from $0,-8,+8$, to $0 \mathrm{~V}$ ), it can be seen that the device does not return to its low conductivity state upon application of positive bias voltage. In a third consecutive scan (from $0,+8,-8$, to $0 \mathrm{~V}$ ), no hysteresis is observed for the current densities under forward bias, indicating that the high conducting level persists when zero or positive bias voltage is applied to the device. Finally, a fourth scan (from $0,+8,-8$, to $0 \mathrm{~V}$ ) shows again a hysteresis in the current density under both forward and reverse biases. We conclude that the reversible changes in resistance are effected by periods of bias voltage stress of both polarities.

The gradual and bipolar nature of the changes in resistivity are also evident from pulse measurements. Here, alter- 


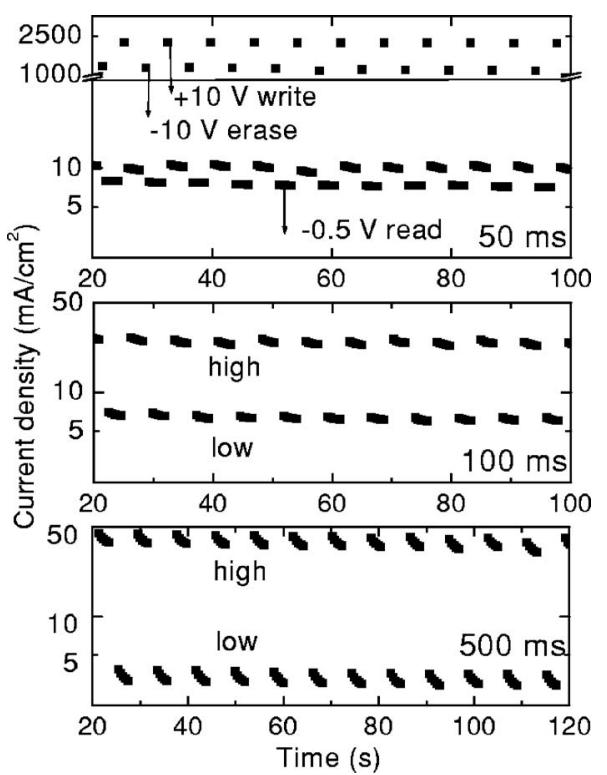

FIG. 7. (a)-(c) Current density of the $\mathrm{ZnO}$ :PS (2:1 by weight) device upon application of a cycle of voltage pulses: a $-10 \mathrm{~V}$ (erase), five $-0.5 \mathrm{~V}$ (read) pulses, a $+10 \mathrm{~V}$ (write), and five $-0.5 \mathrm{~V}$ (read) pulses. Duration of the $-0.5 \mathrm{~V}$ pulses: $0.1 \mathrm{~s}$. Duration of the +10 and $-10 \mathrm{~V}$ pulses is varied from 50 (a), 100 (b), to $500 \mathrm{~ms}$ (c). In between the pulses, the device is kept at zero bias voltage.

nating voltage pulses of +10 and $-10 \mathrm{~V}$ are applied to bring the diode to a state with high or low conductivity. In the experiment, the time duration of bias voltage pulses is varied, using the same interval for both the +10 and $-10 \mathrm{~V}$ pulses. In between the $+10 /-10 \mathrm{~V}$ pulses, the device is kept at zero bias and the conductivity is probed with short $-0.5 \mathrm{~V}$ pulse (100 ms in duration). In Fig. 7 we show the current density of the high and low conductivity levels as a function of the time duration of the $+10 /-10 \mathrm{~V}$ pulses. We find that the ratio of the current density in the high and low conductivity states (on/off) depends on the pulse duration, consistent with a gradual change in resistivity upon application of a bias voltage stress exceeding $5 \mathrm{~V}$ in amplitude. The observation that the on/off ratio changes with the weight content of $\mathrm{ZnO}$ of the active layer (see Fig. 8) supports the view that the memory effects involve currents that flow via interpar-

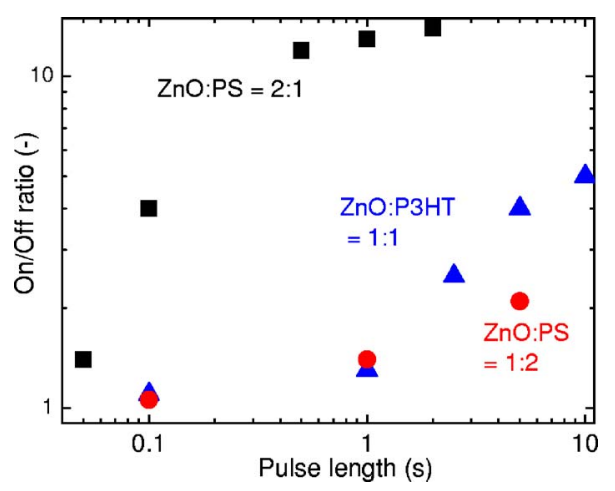

FIG. 8. (Color online) On/off ratio vs temporal width of the write/erase pulses for devices with $\mathrm{ZnO}: \mathrm{PS}=1: 2$ (О), $\mathrm{ZnO}: \mathrm{PS}=2: 1$ (ם), and $\mathrm{ZnO}: \mathrm{P} 3 \mathrm{HT}=1: 1(\boldsymbol{\Delta})$, (by weight). Write/erase voltages are $\pm 10 \mathrm{~V}(\mathrm{PS})$ $\pm 8 \mathrm{~V}$ (P3HT). The on/off ratio is calculated from the current density at $-0.5 \mathrm{~V}$ bias.
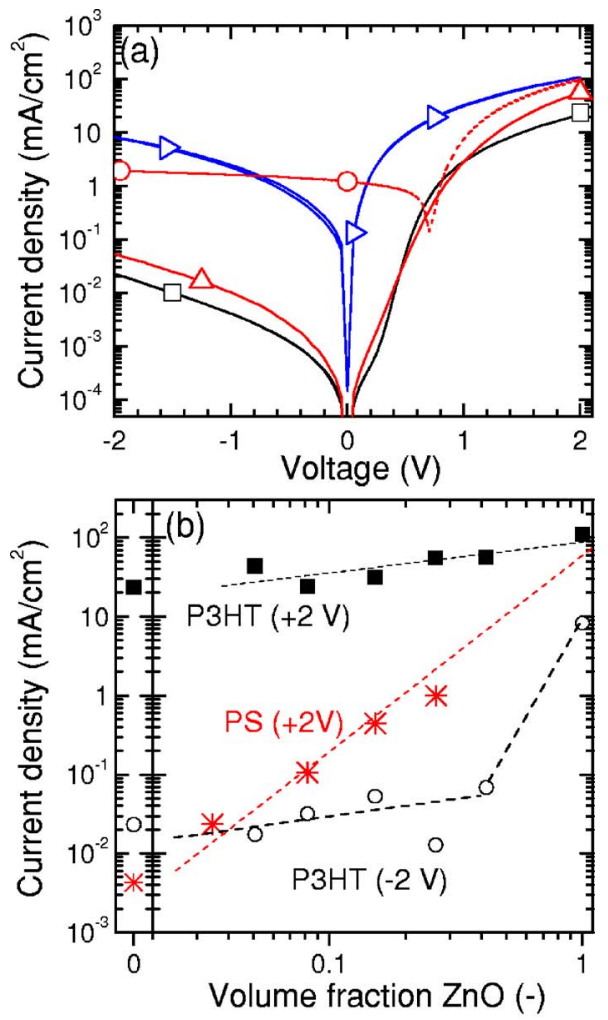

(c)

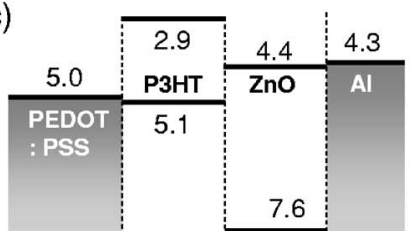

FIG. 9. (Color online) (a) $J-V$ characteristics with various $\mathrm{ZnO}$ loading, $\mathrm{ZnO}: \mathrm{P} 3 \mathrm{HT}=0: 1(\square), 1: 1(\triangle)$, and 1:0 $(\triangleright)$ (by weight). The dotted line (---O---) shows the current density for $\mathrm{ZnO}: \mathrm{P} 3 \mathrm{HT}=1: 1$ under illumination with filtered light $(\lambda>400 \mathrm{~nm})$ from a tungsten-halogen source. (b) Current density for various ratios of $\mathrm{ZnO}: \mathrm{P} 3 \mathrm{HT}$ at $+2 \mathrm{~V}(\boldsymbol{\square})$ and $-2 \mathrm{~V}(\mathrm{O})$ biases and for $\mathrm{ZnO}: \mathrm{PS}$ at $+2 \mathrm{~V}(*)$. The dotted lines serve as a guide to the eye. (c) Band diagram, illustrating the energetic position of the conduction and valence bands of $\mathrm{P} 3 \mathrm{HT}$ and $\mathrm{ZnO}$ with respect to the vacuum level in $\mathrm{eV}$.

ticle contacts between the $\mathrm{ZnO}$ nanocrystals. With a higher $\mathrm{ZnO}$ loading, a measurable on/off ratio can be induced with shorter voltage pulses.

\section{$\mathrm{J}-\mathrm{V}$ characteristics of diodes with $\mathrm{ZnO}: \mathrm{P} 3 \mathrm{HT}$ as active layer}

P3HT is a $\pi$-conjugated polymer with semiconducting properties, which can sustain a current of positive charge carriers. When applied as an active layer in the device structure used here, we observe rectification [see Fig. 9(a)] and this can be ascribed to injection of positive charge carriers through the PEDOT:PSS contact. Upon admixing of $\mathrm{ZnO}$ particles into the P3HT film, the current density through the diode at $+2 \mathrm{~V}$ bias goes up, which can be ascribed to a contribution of electrons moving via the $\mathrm{ZnO}$ to the total current density. This mixture of a $p$ - and a $n$-type material gives rise to a photovoltaic effect ${ }^{68}$ [Fig. 9(a)] resulting from efficient photoinduced charge generation at the $\mathrm{ZnO}$ :P3HT interface and the transport of holes towards the PEDOT:PSS electrode via the P3HT and transport of electrons via the 


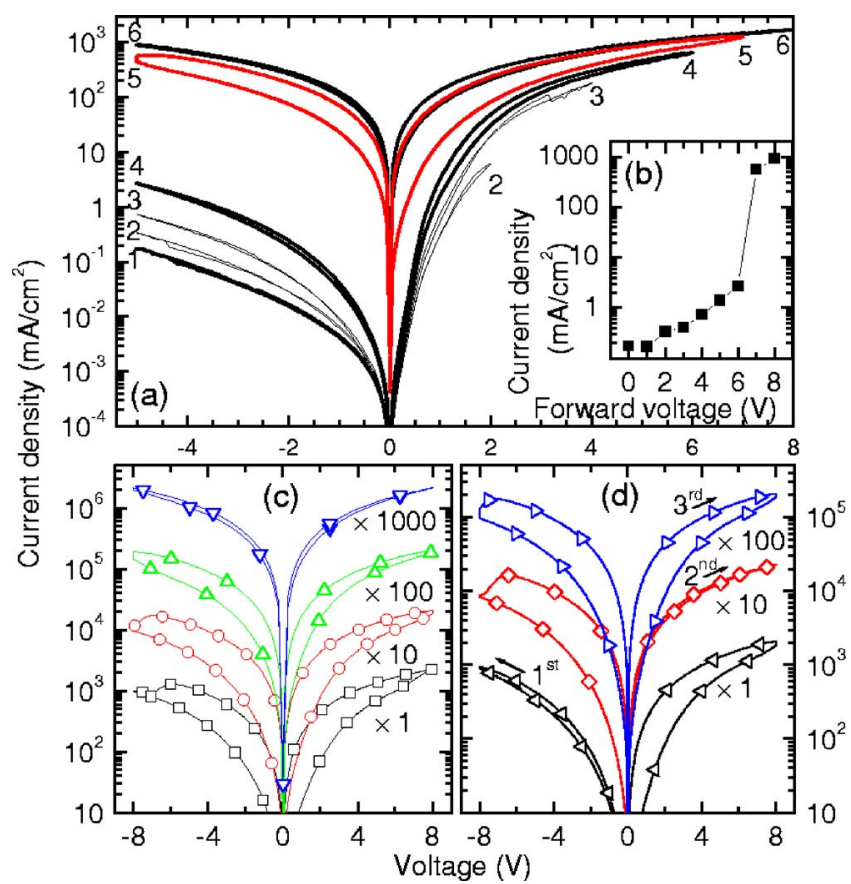

FIG. 10. (Color online) $J-V$ characteristics of a $\mathrm{ZnO}$ :P3HT (1:1 by weight) device. (a) Sequential, cyclic $J-V$ scans $(0 \rightarrow+X \rightarrow-5 \rightarrow 0 \mathrm{~V})$ with $X=0,2$, $4,6,7$, and $8 \mathrm{~V}$ illustrating the forming reaction. (b) Corresponding current density at $-5 \mathrm{~V}$ as a function of amplitude $X$ in the cyclic scan shown in (a) (c) Cyclic $J-V$ scans (from $0,+8,-8$, to $0 \mathrm{~V}$ ) at various speeds: $0.2 \mathrm{~V} / \mathrm{s}$ $(\square), 0.3 \mathrm{~V} / \mathrm{s}(\bigcirc), 0.5 \mathrm{~V} / \mathrm{s}(\triangle)$, and $1.3 \mathrm{~V} / \mathrm{s}(\nabla)$, offset for clarity. Sequential, cyclic $J-V$ Scan with different scan direction: (from $0,+8,-8$, to $0 \mathrm{~V}$, preparation, not shown), (from $0,-8,+8$, to $0 \mathrm{~V}, \triangleleft$ ), (from $0,+8,-8$, to $0 \mathrm{~V}, \diamond$ ), and (from $0,+8,-8$, to $0 \mathrm{~V}, \triangleright$ ). Curves are offset for clarity and the arrow indicates the initial direction of the bias voltage sweep.

$\mathrm{ZnO}$ towards the $\mathrm{Al}$ electrode. Interestingly, for a 1:1 mixture of $\mathrm{ZnO}: \mathrm{P3HT}$, illumination with visible light $(\lambda>400 \mathrm{~nm})$ does not modify the dark $J$ - $V$ characteristics, whereas illumination with UV light results in a large rise of the conductivity of the film, similar to the surge observed upon illumination of the $\mathrm{ZnO}$ :PS layers. These observations are consistent with the interpretation of the light induced changes in $\mathrm{ZnO}$ particles as the result of positive charge carriers in the $\mathrm{ZnO}$.

The $\mathrm{ZnO}$ :P3HT diodes also undergo a forming process upon application of positive bias voltage stress (Fig. 10). Here, we see a gradual transition to a much higher conductivity level and, after the forming step, hysteresis in the $J-V$ characteristic is also observed. The magnitude of the hysteresis effect depends on the scan speed used in the cyclic $J$ - $V$ scan, which shows that the memory effect is the result of changes inside the device that take place at a relatively slow rate [Fig. 10(c)]. Also here, we find that hysteresis can only be observed when applying positive and negative bias voltage stresses in an alternating way [Fig. 10(d)] and that the conductivity changes in a gradual way rather than by sudden jumps [Fig. 11].

Finally, we find that the polymer used has an influence on the "lifetime" of the high and low conductivity states prepared by the positive and negative bias pulses. In Fig. 12, we show the current densities for the two conductivity levels, probed at $-0.5 \mathrm{~V}$. Using PS as a matrix, we observe a rapid initial decrease of the conductivity in the first $10 \mathrm{~s}$ after the preparation pulses for both the high and the low conductivity

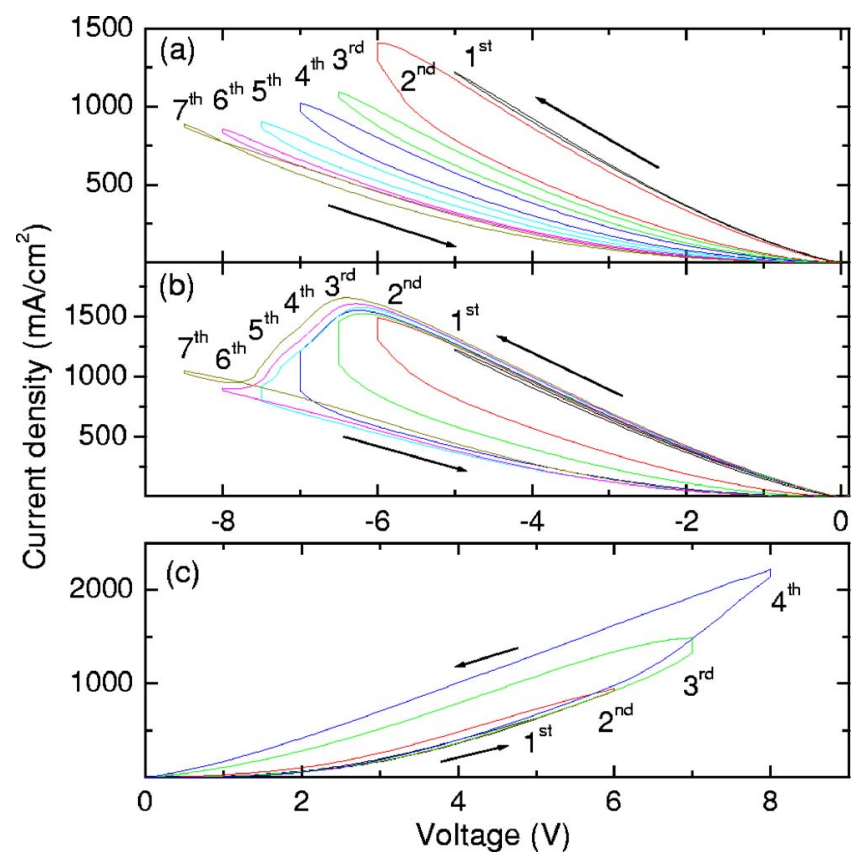

FIG. 11. (Color online) Sequential, cyclic scans $J$ - $V$ characteristics on a formed $\mathrm{ZnO}: \mathrm{P} 3 \mathrm{HT}$ (1:1 by weight) device (a) over the negative bias voltage range $(0 \rightarrow-X \rightarrow 0 \mathrm{~V})$ with $X=5,6,6.5,7,7.5,8$, and $8.5 \mathrm{~V}$ after one initial forward scan to $+8 \mathrm{~V}$; (b) over the positive and negative bias voltage range (from $0,+8,-X$, to $0 \mathrm{~V}$ ) with $X=5,6,6.5,7,7.5,8$, and $8.5 \mathrm{~V}$; and (c) over the range (from $0,+X,-8$, to $0 \mathrm{~V}$ ) with $X=5,6,7$, and $8 \mathrm{~V}$.

states. This is followed by a second decay process occurring on the time scale of an hour. The latter drop can tentatively be assigned to oxygen rebinding. With P3HT as the matrix, we also observed the rapid decay process, but the slow decay is very much suppressed and the two current density levels can now be distinguished for times exceeding $14 \mathrm{~h}$. This difference between the two polymers may be related to a difference in the uptake of oxygen. The graph nicely illustrates that memory effect in these hybrid materials can be influenced by the choice of the host matrix.

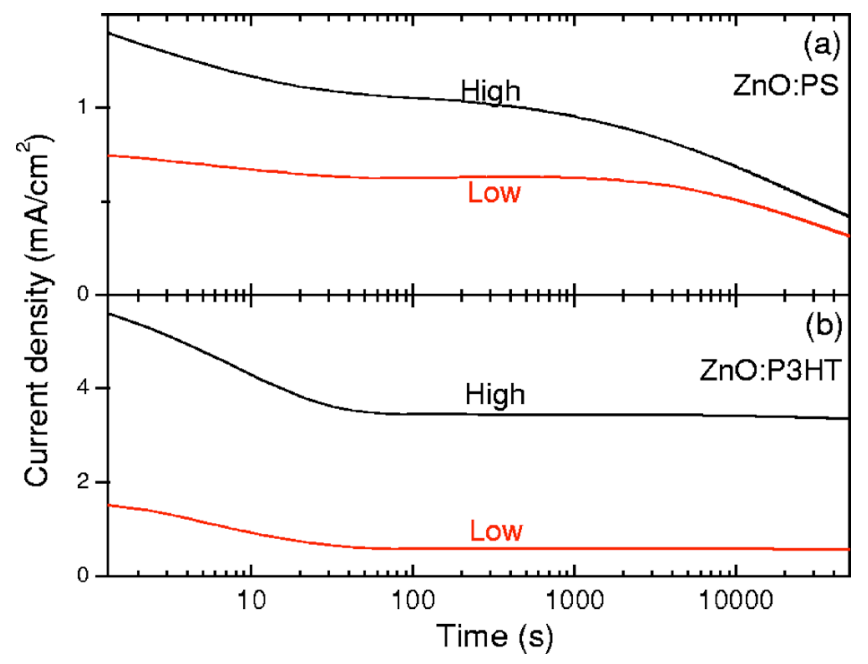

FIG. 12. (Color online) Stability of the high and low conductivity states in formed diodes with an active layer of (a) $\mathrm{ZnO}: \mathrm{PS}=1: 2$ and (b) $\mathrm{ZnO}: \mathrm{P} 3 \mathrm{HT}=1: 1$ (by weight). Current densities are probed by application of short $(100 \mathrm{~ms})-0.5 \mathrm{~V}$ pulses, in between these read pluses the device is kept at zero bias. The high and low conductivity states are prepared by application of $\pm 10 \mathrm{~V}, 10 \mathrm{~s}$ voltage pulses for $\mathrm{ZnO}$ :PS and $\pm 8 \mathrm{~V}$ pulses for ZnO:P3HT. 


\section{DISCUSSION}

In the section above, we have presented experimental evidence relating the forming reaction in the $\mathrm{ZnO}$ :polymer devices to an increase in the concentration of mobile electrons due to the desorption of surface bound oxygen from the $\mathrm{ZnO}$ nanoparticles induced by positive charge carriers. An active role for holes in dynamic effects in the resistivity of nanoparticulate materials containing $\mathrm{ZnO}$ is also known from research on $\mathrm{ZnO}$ varistors. ${ }^{69,70}$ Also, here molecular oxygen absorbed on the surface of $\mathrm{ZnO}$ particles is thought to play a role. $^{71,72}$

The reversible changes in the resistivity after the forming reaction requires application of bias voltage stress of both polarities. The changes themselves occur in a gradual manner and relatively slowly, which is consistent with an electrochemical process. Considering the band diagram (Figs. 1 and 9), it seems likely that, in the formed diode, a depletion zone will arise in the $\mathrm{ZnO}$ :polymer layer near the PEDOT:PSS contact. Hence, electrochemical processes occurring near this electrode are therefore expected to have a strong influence on the current density. A possible explanation may be the migration of dopants and native defects in the $\mathrm{ZnO}$ induced by the applied voltage or current. For instance, hydrogen is relatively mobile in $\mathrm{ZnO},{ }^{73,74}$ and may contribute to the $n$-type conductivity of $\mathrm{ZnO}$ (Ref. 75) and is available from the PEDOT:PSS electrode. Migration of oxygen vacancies under the influence of an applied field can contribute to memory effects in metal oxides. ${ }^{76}$ Study of the degradation of the performance of varistors has yielded experimental evidence for migration of $\mathrm{Zn}$ interstitials as a cause for electrically induced changes in the electrical properties of $\mathrm{ZnO}$ based materials. ${ }^{77,78}$

\section{CONCLUSIONS}

The resistivity of diode structures with an active layer of $\mathrm{ZnO}$ nanoparticles mixed with polymer can be altered by application of bias voltage stress. A forming step leading to much higher conductivity levels occurs under application of forward bias stress, and this process can be reversed by exposure to oxygen. After forming, the conductivity of the device can be reversibly changed by application of positive and negative bias voltage stresses. These memory effects result from changes induced in the $\mathrm{ZnO}$ nanoparticles and their interparticle contacts, which provide a percolation path for electrical conduction of electrons. The $\mathrm{ZnO}$ :polymer layers are solution processable and the memory effects can be influenced by modifying the (nanoscopic) chemical structure of the $\mathrm{ZnO}$ polymer film. This makes the MIM device amenable to chemical engineering, in contrast to the case of bulk metal oxides where one has little chemical control over the switching properties. Rewritable data storage could be demonstrated and minimum "write/erase" times of $50 \mathrm{~ms}$ and retention times $>14 \mathrm{~h}$ are possible.

\section{ACKNOWLEDGMENTS}

We thank Dr. Waldo Beek for valuable discussions and Edsger Smits from Philips Research Laboratories for help with the FET measurement. This research forms part of the research programme of the Dutch Polymer Institute (DPI), Project No. 523.

${ }^{1}$ H. Pagnia and N. Sotnik, Phys. Status Solidi A 108, 11 (1988).

${ }^{2}$ G. Dearnaley, A. M. Stoneham, and D. V. Morgan, Rep. Prog. Phys. 33, 1129 (1970).

${ }^{3}$ R. E. Thurstans and D. P. Oxley, J. Phys. D 35, 802 (2002).

${ }^{4}$ A. Beck, J. G. Bednorz, C. Gerber, C. Rossel, and D. Widmer, Appl. Phys. Lett. 77, 139 (2000).

${ }^{5}$ A. Baikalov, Y. Q. Wang, B. Shen, B. Lorenz, S. Tsui, Y. Y. Sun, Y. Y. Xue, and C. W. Chu, Appl. Phys. Lett. 83, 957 (2003).

${ }^{6}$ K. Szot, W. Speier, G. Bihlmayer, and R. Waser, Nat. Mater. 5, 312 (2006).

${ }^{7}$ K. Kinoshita, T. Tamura, M. Aoki, Y. Sugiyama, and H. Tanaka, Appl. Phys. Lett. 89, 103509 (2006).

${ }^{8}$ D. C. Kim, S. Seo, S. E. Ahn, D.-S. Suh, M. J. Lee, B.-H. Park, I. K. Yoo, I. G. Baek, H.-J. Kim, E. K. Yim, J. E. Lee, S. O. Park, H. S. Kim, U.-I. Chung, J. T. Moon, and B. I. Ryu, Appl. Phys. Lett. 88, 202102 (2006).

${ }^{9}$ W. R. Hiatt and T. W. Hickmott, Appl. Phys. Lett. 6, 106 (1965).

${ }^{10}$ T. W. Hickmott, J. Appl. Phys. 88, 2805 (2000).

${ }^{11}$ K. L. Chopra, J. Appl. Phys. 36, 184 (1965).

${ }^{12}$ F. Argall, Solid-State Electron. 11, 535 (1968).

${ }^{13}$ K. Tsunoda, Y. Fukuzumi, J. R. Jameson, Z. Wang, P. B. Griffin, and Y. Nishi, Appl. Phys. Lett. 90, 113501 (2007).

${ }^{14}$ B. J. Choi, S. Choi, K. M. Kim, Y. C. Shin, C. S. Hwanga, S.-Y. Hwang, S. Cho, S. Park, and S.-K. Hong, Appl. Phys. Lett. 89, 012906 (2006).

${ }^{15}$ J. F. Gibbons and W. E. Beadle, Solid-State Electron. 7, 785 (1964).

${ }^{16}$ J. H. Jung, J. H. Kim, T. W. Kim, M. S. Song, Y. H. Kim, and S. Jin, Appl. Phys. Lett. 89, 122110 (2006).

${ }^{17}$ T. Hada, K. Wasa, and S. Hayakawa, Jpn. J. Appl. Phys. 10, 521 (1971).

${ }^{18}$ S. Q. Liu, N. J. Wu, and A. Ignatiev, Appl. Phys. Lett. 76, 2749 (2000).

${ }^{19}$ M. Hamaguchi, K. Aoyama, S. Asanuma, Y. Uesu, and T. Katsufuji, Appl. Phys. Lett. 88, 142508 (2006).

${ }^{20}$ H. K. Henisch and W. R. Smith, Appl. Phys. Lett. 24, 589 (1974).

${ }^{21}$ J. McGinness, P. Corry, and P. Proctor, Science 183, 853 (1974).

${ }^{22}$ R. Müller, S. De Jonge, K. Myny, D. J. Wouters, J. Genoe, and P. Heremans, Appl. Phys. Lett. 89, 223501 (2006).

${ }^{23}$ A. Bandyopadhyay and A. J. Pal, Appl. Phys. Lett. 82, 1215 (2003).

${ }^{24}$ D. Bloor, K. Donnelly, P. J. Hands, P. Laughlin, and D. Lussey, J. Phys. D 38, 2851 (2005).

${ }^{25}$ Y. Yang, J. Ouyang, L. Ma, R. J.-H. Tseng, and C.-W. Chu, Adv. Funct. Mater. 16, 1001 (2006).

${ }^{26}$ L. D. Bozano, B. W. Kean, M. Beinhoff, K. R. Carter, P. M. Rice, and J. C. Scott, Adv. Funct. Mater. 15, 1933 (2005).

${ }^{27}$ W. Tang, H. Z. Shi, G. Xu, B. S. Ong, Z. D. Popovic, J. C. Deng, J. Zhao, and G. H. Rao, Adv. Mater. (Weinheim, Ger.) 17, 2307 (2005).

${ }^{28}$ K. Mohanta, S. K. Majee, S. K. Batabyal, and A. J. Pal, J. Phys. Chem. B 110, 18231 (2006)

${ }^{29}$ A. Prakash, J. Ouyang, J.-L. Lin, and Y. Yang, J. Appl. Phys. 100, 54309 (2006).

${ }^{30}$ Y. Yang, L. Ma, and J. Wu, MRS Bull. 29, 833 (2004).

${ }^{31}$ J. Wu, K. Mobley, and R. L. McCreery, J. Chem. Phys. 126, 024704 (2007).

${ }^{32}$ J. E. Ralph and J. M. J. Woodcock, J. Non-Cryst. Solids 7, 236 (1972).

${ }^{33}$ D. S. Kim, Y. H. Kim, C. E. Lee, and Y. T. Kim, Phys. Rev. B 74, 174430 (2006).

${ }^{34}$ J. G. Simmons and R. R. Verderber, Proc. R. Soc. London, Ser. A 301, 77 (1967).

${ }^{35}$ S. Brauer, H. Pagnia, and N. Sotnik, Int. J. Electron. 76, 707 (1994).

${ }^{36}$ D. S. Jeong, B. J. Choi, and C. S. Hwang, J. Appl. Phys. 100, 113724 (2006).

${ }^{37}$ S. Tsui, Y. Q. Wang, X. Y. Yue, and C. W. Chu, Appl. Phys. Lett. 89, 123502 (2006).

${ }^{38}$ M. Cölle, M. Büchel, and D. M. de Leeuw, Org. Electron. 7, 305 (2006).

${ }^{39}$ W.-J. Joo, T.-L. Choi, J. Lee, S. K. Lee, M.-S. Jung, N. Kim, and J. M. Kim, J. Phys. Chem. B 110, 23812 (2006).

${ }^{40}$ S. Karthauser, B. Lussem, M. Weides, M. Alba, A. Besmehn, R. Oligschlaeger, and R. Waser, J. Appl. Phys. 100, 94504 (2006).

${ }^{41}$ F. Verbakel, S. C. J. Meskers, and R. A. J. Janssen, Appl. Phys. Lett. 89, 102103 (2006)

${ }^{42}$ M. Villafuerte, S. P. Heluani, G. Juárez, G. Simonelli, G. Braunstein, and S. Duhalde, Appl. Phys. Lett. 90, 052105 (2007). 
${ }^{43}$ W. K. Liu, K. M. Whitaker, K. R. Kittilstved, and D. R. Gamelin, J. Am. Chem. Soc. 128, 3910 (2006).

${ }^{44}$ Y. Takahashi, M. Kanamori, A. Kondoh, H. Minoura, and Y. Ohya, Jpn. J. Appl. Phys., Part 1 33, 6611 (1994).

${ }^{45}$ F. Verbakel, S. C. J. Meskers, and R. A. J. Janssen, J. Phys. Chem. C. 111, 10150 (2007).

${ }^{46}$ W. J. E. Beek, M. M. Wienk, M. Kemerink, X. Yang, and R. A. J. Janssen, J. Phys. Chem. B 109, 9505 (2005).

${ }^{47}$ V. Ischenko, S. Polarz, D. Grote, V. Stavarache, K. Fink, and M. Driess, Adv. Funct. Mater. 15, 1945 (2006).

${ }^{48}$ S. B. Orlinskii, H. Blok, J. Schmidt, P. G. Baranov, C. D. M. Donega, and A. Meijerink, Phys. Rev. B 74, 045204 (2006).

${ }^{49}$ L. S. Vlasenko and G. D. Watkins, Phys. Rev. B 72, 035203 (2005).

${ }^{50}$ M. Shim and P. Guyot-Sionnest, J. Am. Chem. Soc. 123, 11651 (2001).

${ }^{51}$ S. C. J. Meskers, J. K. J. van Duren, R. A. J. Janssen, F. Louwet, and L. Groenendaal, Adv. Mater. (Weinheim, Ger.) 15, 613 (2003).

${ }^{52}$ B. Sun and H. Sirringhaus, J. Am. Chem. Soc. 128, 16231 (2006).

${ }^{53}$ B. S. Ong, C. Li, Y. Li, Y. Wu, and R. Loutfy, J. Am. Chem. Soc. 129, 2750 (2007).

${ }^{54}$ S. A. Studenikin, N. Golego, and M. Cocivera, J. Appl. Phys. 87, 2413 (2000).

${ }^{55}$ P. Sharma, K. Sreenivas, and K. V. Rao, J. Appl. Phys. 93, 3963 (2003).

${ }^{56}$ L. J. A. Koster, Ph.D. thesis, Groningen University, 2007; http:// dissertations.ub.rug.nl/faculties/science/2007/l.j.a.koster/

?FullItemRecord $=\mathrm{ON}$

${ }^{57}$ P. W. M. Blom and M. C. J. M. Vissenberg, Mater. Sci. Eng., R. 27, 53 (2000).

${ }^{58}$ V. R. Nikitenko, H. Heil, and H. von Seggern, J. Appl. Phys. 94, 2480 (2003).

${ }^{59}$ J. Vilčákova, P. Sáha, V. Křesálek, and O. Quadrat, Synth. Met. 113, 83 (2000).
${ }^{60}$ F. El-Tantawy, K. Kamada, and H. Ohnabe, Mater. Lett. 56, 112 (2002).

${ }^{61}$ M. Xiao, L. Sun, J. Liu, Y. Li, and K. Gong, Polymer 43, 2245 (2002).

${ }^{62}$ W. Jia, R. Tchoudakov, E. Segal, R. Joseph, M. Narkis, and A. Siegmann, Synth. Met. 132, 269 (2003).

${ }^{63}$ A. Mikrajuddin, F. G. Shi, S. Chungpaiboonpatana, K. Okuyama, C. Davidson, and J. M. Adams, Mater. Sci. Semicond. Process. 2, 309 (1999).

${ }^{64}$ Z. Rubin, S. A. Sunshine, M. B. Heaney, I. Bloom, and I. Balberg, Phys. Rev. B 59, 12196 (1999).

${ }^{65}$ V. A. Soloukhin, Ph.D. thesis, Eindhoven University of Technology, 2003; http://alexandria.tue.nl/extra2/200312898.pdf

${ }^{66}$ Y. Sato, K. Kinoshita, M. Aoki, and Y. Sugiyama, Appl. Phys. Lett. 90, 033503 (2007).

${ }^{67}$ P. G. Lecomber, A. E. Owen, W. E. Spear, J. Hajto, A. J. Snell, W. K. Choi, M. J. Rose, and S. Reynolds, J. Non-Cryst. Solids 77-78, 1373 (1985).

${ }^{68}$ W. J. E. Beek, M. M. Wienk, and R. A. J. Janssen, Adv. Funct. Mater. 16, 1112 (2006)

${ }^{69}$ T. K. Gupta, J. Am. Ceram. Soc. 73, 1817 (1990).

${ }^{70}$ D. R. Clarke, J. Am. Ceram. Soc. 82, 485 (1999).

${ }^{71}$ M. A. Ramirez, A. Z. Simoes, P. R. Bueno, M. A. Marquez, M. O. Orlandi, and J. A. Varela, J. Mater. Sci. 41, 6221 (2006).

${ }^{72}$ F. Stucki and F. Greuter, Appl. Phys. Lett. 57, 446 (1990).

${ }^{73}$ N. H. Nickel, Phys. Rev. B 73, 195204 (2006).

${ }^{74}$ Y. L. Wang, F. Ren, H. S. Kim, S. J. Pearton, and D. P. Norton, Appl. Phys. Lett. 90, 092116 (2007).

${ }^{75}$ C. G. Van de Walle, Phys. Rev. Lett. 85, 1012 (2000).

${ }^{76}$ Y. B. Nian, J. Strozier, N. J. Wu, X. Chen, and A. Ignatiev, Phys. Rev. Lett. 98, 146403 (2007).

${ }^{77}$ P. Erhart and K. Albe, Appl. Phys. Lett. 88, 201918 (2006).

${ }^{78}$ T. K. Gupta and W. G. Carslon, J. Mater. Res. 20, 745 (1985). 